\title{
Article \\ Medication Errors Detected in Primary Health Care after Hospital Discharge
}

\author{
María del Carmen González-López ${ }^{1}$, Carlos Ruíz-González ${ }^{1}$, Bruno José Nievas-Soriano ${ }^{2, *(\mathbb{D} \text {, }}$ \\ Sonia García-Duarte ${ }^{3}$ and Tesifón Parrón-Carreño ${ }^{2}$ (1) \\ 1 Primary Health Care District of Almeria, Andalusian Health Service, 04006 Almería, Spain; \\ mariac.gonzalez.lopez.sspa@juntadeandalucia.es (M.d.C.G.-L.); carlos231993@gmail.com (C.R.-G.) \\ 2 Department of Nursing Science, Physiotherapy and Medicine, University of Almería, 04006 Almería, Spain; \\ tpc468@ual.es \\ 3 Obstetrics and Gynecology Unit, Hospital Torrecárdenas, 04009 Almería, Spain; sgarciaduarte@hotmail.com \\ * Correspondence: brunonievas@ual.es
}

Citation: González-López, M.d.C.; Ruíz-González, C.; Nievas-Soriano,

B.J.; García-Duarte, S.; Parrón-

Carreño, T. Medication Errors Detected in Primary Health Care after Hospital Discharge. Appl. Sci. 2021, 11, 11306. https://doi.org/ 10.3390/app112311306

Academic Editor: Federico Divina

Received: 14 November 2021 Accepted: 26 November 2021 Published: 29 November 2021

Publisher's Note: MDPI stays neutral with regard to jurisdictional claims in published maps and institutional affiliations.

Copyright: (c) 2021 by the authors. Licensee MDPI, Basel, Switzerland. This article is an open access article distributed under the terms and conditions of the Creative Commons Attribution (CC BY) license (https:/ / creativecommons.org/licenses/by/ $4.0 /)$.

\begin{abstract}
Background: Medication conciliation allows finding discrepancies and medication errors in healthcare transitions, but there are few studies performed after hospital discharge, in the context of primary health care. Therefore, the main aim of this research was to evaluate the process of medication conciliation in primary health care, after hospital discharge. We further sought to analyze some demographic aspects of the patients that could be associated with potential discrepancies. Methods: A cross-sectional study was performed using the database which contained the records generated by the medication reconciliations performed by the physicians of the Andalusian Public Health Service, in Spain. Results: A total of 6115 medication conciliations were analyzed, and discrepancies were found in $73.7 \%$ of them. A total of $50.6 \%$ were medication errors, the most frequent being medication omission. Medication errors were more prevalent in women of 65 years and older. Conclusions: After hospital discharge, most patients show medication discrepancies in their records, particularly older women. To prevent this, primary health care plays an essential role in the conciliation process, therefore more research is needed in this context.
\end{abstract}

Keywords: medication conciliation; primary health care; discrepancies; medication errors

\section{Introduction}

Concerns about the adverse effects of the drugs used in health care are increasing among healthcare professionals [1-3]. Trying to prevent them, the World Health Organization (WHO) reported specific measures on the safe usage of drugs, describing the process called Medication Reconciliation [1]. In 2017, this same organization highlighted that improving the communication at the different healthcare transition points was essential to avoid harm originated by drugs [4]. Healthcare transitions do generate a risk for patient safety, as medication errors are likely to occur, due to the lack of communication among healthcare professionals, and the potential loss of information [4-6].

The reconciliation of medication contrasts the patients' medication to the medication prescribed after a healthcare transition, to analyze and solve discrepancies and medication errors [7-10]. A medication error is a preventable event, related to the prescription and the use of drugs, that can cause harm to patients. It can be related to clinical and procedural issues but, in most cases, it is due to the use of inappropriate drugs [2-4,9]. These errors cost billions of euros and an incalculable human cost [9]. It is estimated that, in the European Union, up to $12 \%$ of patients admitted to hospitals suffer from adverse effects related to drugs [11]; and 40-60\% of the patients' medications can show discrepancies at hospital discharge [12]. To identify and correct medication discrepancies, the National Institute for Health and Care Excellence (NICE), the Accreditation Canada, and the Joint Commission propose to perform medication reconciliation in healthcare transitions $[2,5,8,13]$. 
In Spain, $9.4 \%$ of patients admitted to hospitals have had adverse effects, and onethird of them could be related to the use of medication. It is estimated that $25.6 \%$ of these errors could have been prevented [14,15]. For this reason, the Spanish Ministry of Health elaborated the Patient security strategy guide, which included the reconciliation of medication as a step between hospital and primary health care transition [3]. As polymedicated and chronic patients are more susceptible to experiencing medication errors, in these specific groups is more relevant to perform the reconciliation of medication at any healthcare transition $[7,12,13,16,17]$.

The reconciliation of medication is performed by primary health care physicians, following a structured and systematic method, using a computer program provided by the Andalusian Health Service. This tool has a checklist, which guarantees the adherence to the protocol, that must be fulfilled by the physicians. All the discrepancies must be recorded. The conciliations performed are recorded in a database that is subsequently analyzed. The process of conciliation is based on a three-step methodology, endorsed by various national and international institutions [12]. In the first step, a full list of the medication is obtained from the digital medical records. This list includes dosages, posology, and dosage form. A personal interview with the patient or its caregiver, can also be performed. The second step compares that medication list with the new prescriptions performed at the hospital discharge, to find and solve potential discrepancies. The medication errors, considered as standard to perform this analysis, are the following: medication omission, contraindicated medication, discrepancies in dosages, drug interactions, and duplicated therapeutics [17]. In the third step, the physician informs the patients about the modifications performed in their medication [11-13]. Involving the patients in the management of their medication increases their safety and their adherence to the treatment [18].

Nevertheless, few studies have analyzed the process of medication reconciliation in the primary health care context. Therefore, the main aim of this research was to analyze the results of the systematic processing of the reconciliation of medication, performed by the physicians of primary health care, identifying discrepancies and medication errors, generated after hospital discharge, before they could affect the patients. We further sought to analyze some demographic aspects of the patients that could be associated with the occurrence of these errors.

\section{Materials and Methods}

A cross-sectional study was performed using the database which contains all the records generated by the medication reconciliations performed by the physicians of the Andalusian Public Health Service, in Spain. This research was performed in the Primary Health District of Almería, which attends a population of 301,457 inhabitants, distributed among 18 primary healthcare centers, and a reference hospital.

For this research, every patient discharged from four hospital services (cardiology, internal medicine, digestive and respiratory) during a year (May 2019-February 2020) were analyzed. The data collected was the following: age, gender, if medication reconciliation was performed, medication discrepancies, medication errors (medication omission, contraindicated drugs, duplicated therapeutics, differences in dosages, potential drug interactions), and if the discrepancies were corrected.

Univariate analysis was performed describing the variables collected. For descriptive analysis of the collected variables, central tendency and dispersion measures were used for quantitative variables, absolute frequencies were used for qualitative variables, and $95 \%$ confidence intervals $(\mathrm{CI})$ were calculated for means and proportions. The goodness of fit to normality for the variables was calculated using the Kolmogorov-Smirnov test. For the analysis of the medication errors, the patients were grouped into two age strata: those who were younger than 65 , and those aged 65 and older. The analysis was also performed considering their gender. To perform bivariate analysis, the nonparametric Mann-Whitney test was used to compare the main quantitative variables. For qualitative variables, the 
Pearson Chi-squared test and Fisher's exact test were used. Statistical analyses were performed using SPSS version 26 (IBM Inc., Armonk, NY, USA).

This was a cross-sectional study based on clinical data previously existing in medical records. As no personal information was collected, data was anonymous, and no informed consent was required. All the procedures described in this study were approved by the Research and Ethics Committee of the Province of Almeria (Spain), with protocol code TFG-ACME-2020, and approval number 07/2021 (27 January 2021).

\section{Results}

\subsection{Most Reported Medication Errors}

A total of 6416 hospital-discharged patients' records were analyzed. Of these patients, $49.6 \%$ were from the Internal Medicine Service $(\mathrm{n}=3182), 20.1 \%$ from the Digestive Service $(\mathrm{n}=1290), 16.0 \%$ from the Cardiology Service $(\mathrm{n}=1027)$ and $14.3 \%$ from the Neumology Service $(n=917)$. A total of $95.3 \%$ of these patients $(n=6115)$ had a reconciliation of medication records performed. Discrepancies were found in $73.7 \%$ of the conciliated patients $(\mathrm{n}=4507)$, and $50.6 \%$ of these discrepancies $(\mathrm{n}=2278)$ were generated by medication errors. Therefore, medication errors were stated in $37.3 \%(n=2281)$ of all the conciliations analyzed. The most-reported medication errors are shown in Table 1.

Table 1. Most reported medication errors.

\begin{tabular}{lcc}
\hline Medication Error & $\mathbf{n}$ & $\mathbf{\%}$ \\
\hline Medication omission & 1387 & 22.7 \\
Contraindicated medication & 466 & 7.6 \\
Differences in dosages & 362 & 6.0 \\
Drug interactions & 32 & 0.5 \\
Duplicated therapeutics & 31 & 0.5 \\
Total medication errors & 2278 & 37.25 \\
Total conciliations analyzed & $\mathbf{6 1 1 5}$ & $\mathbf{1 0 0}$ \\
\hline
\end{tabular}

The mean age of the analyzed patients was 64.6 years, with a standard deviation (S.D.) of 19.07. The youngest patient was 20, and the elder, 103 years old. When the patients were stratified according to their age (Table 2$)$, a total of $35 \%$ of the patients $(n=2139)$ were over 79 years, and only $9.3 \%$ of them $(n=570)$ where under 34 years old.

Table 2. Distribution of patients according to their age.

\begin{tabular}{ccc}
\hline Age Strata & $\mathbf{n}$ & \% \\
\hline 79 & 2139 & 35.0 \\
$65-79$ & 1383 & 22.6 \\
$50-64$ & 1180 & 19.3 \\
$35-49$ & 843 & 13.8 \\
$34-20$ & 570 & 9.3 \\
Total & $\mathbf{6 1 1 5}$ & $\mathbf{1 0 0}$ \\
\hline
\end{tabular}

\subsection{Analysis of Medication Errors}

The mean age of the conciliated patients was 64.6 years, and most of the conciliations analyzed $(57.6 \%)$ were performed in patients older than 65 years. Based on these two aspects, the patients were grouped into two age strata to perform the analysis of the medication errors: those who were younger than 65 , and those aged 65 and older (Table 3). A total of $57.6 \%$ of the conciliations were performed in patients aged 65 and older, and $70.5 \%$ of the medication errors $(\mathrm{n}=1606)$ were found in patients aged 65 and older, versus $29.5 \%(\mathrm{n}=672)$ found in patients below 65 years (Chi-squared test, $p<0.001)$. When analyzing the different types of medication errors, the prevalence of all of them was higher in patients aged 65 and older, being these differences statistically significant (Chi-squared 
test). The most frequent error was the medication omission, found in $27.2 \%$ of patients 65 and older $(n=957)$, and in $16.6 \%$ of patients under $65(n=430)$. The following most frequent errors found were contraindicated medication, found in $10.5 \%$ of patients 65 and older and in $4.3 \%$ of patients under 65 , and differences in dosages, found in $6.8 \%$ of patients 65 and older and in $4.7 \%$ of patients under 65 .

Table 3. Medication errors analyzed by age of patients.

\begin{tabular}{lccc}
\hline \multicolumn{1}{c}{ Medication Error } & $<65$ & $>=65$ & $p^{*}$ \\
\hline Medication omission & $430(16.6 \%)$ & $957(27.2 \%)$ & $<0.01$ \\
Contraindicated medication & $111(4.3 \%)$ & $355(10.5 \%)$ & $<0.01$ \\
Differences in dosages & $121(4.7 \%)$ & $241(6.8 \%)$ & $<0.05$ \\
Drug interactions & $4(0.1 \%)$ & $28(0.8 \%)$ & $<0.01$ \\
Duplicated therapeutics & $6(0.2 \%)$ & $25(0.7 \%)$ & $<0.01$ \\
Total & 672 & 1606 & $<0.001$ \\
\hline
\end{tabular}

* Chi-squared test.

Regarding sex and mean age (Table 4 ), a total of $52.1 \%$ of the medication errors were found in men $(\mathrm{n}=3184)$ and $47.9 \%$ in women $(\mathrm{n}=2931)$. The mean age of the men was 65.6 years, and the mean age of the women was 63.6 years. This difference was statistically significant (Mann-Whitney test, $p<0.05$ ).

Table 4. Mean age and sex of conciliated patients.

\begin{tabular}{ccccc}
\hline Sex & $\mathbf{n}$ & Mean Age & S.D. & $p^{*}$ \\
\hline Women & 2931 & 63.6 & 20.64 & $<0.02$ \\
Men & 3184 & 65.6 & 17.44 & \\
Total & $\mathbf{6 1 1 5}$ & & & \\
\hline
\end{tabular}

* Mann-Whitney test.

The prevalence of the medication errors in the different age and sex groups (Table 5) was different $(p<0.001$; Chi-squared test). As shown in Figure 1, the number of conciliated patients substantially increases from the 50-64 years strata. In this same age strata, and in 65-79 years, the number of men was higher but, in the strata of over 79 years, the percentage of women $(35.8 \%)$ was bigger than men $(34.2 \%)$. The largest number of conciliated patients were 65 years or older.

Table 5. Patient distribution by age strata and sex.

\begin{tabular}{cccc}
\hline Age Strata & Sex & n (\%) & $p^{*}$ \\
\hline \multirow{2}{*}{79} & Men & $1092(17.9 \%)$ & \\
& Women & $1049(17.2 \%)$ & \\
$65-79$ & Men & $783(12.8 \%)$ & \\
& Women & $602(9.8 \%)$ & \\
$50-64$ & Men & $659(10.8 \%)$ & \\
& Women & $519(8.5 \%)$ & \\
$35-49$ & Men & $454(7.4 \%)$ & \\
& Women & $388(6.3 \%)$ & \\
20-34 & Men & $196(3.2 \%)$ & \\
Total & Women & $373(6.1 \%)$ & \\
\hline
\end{tabular}

* Chi-squared test. 


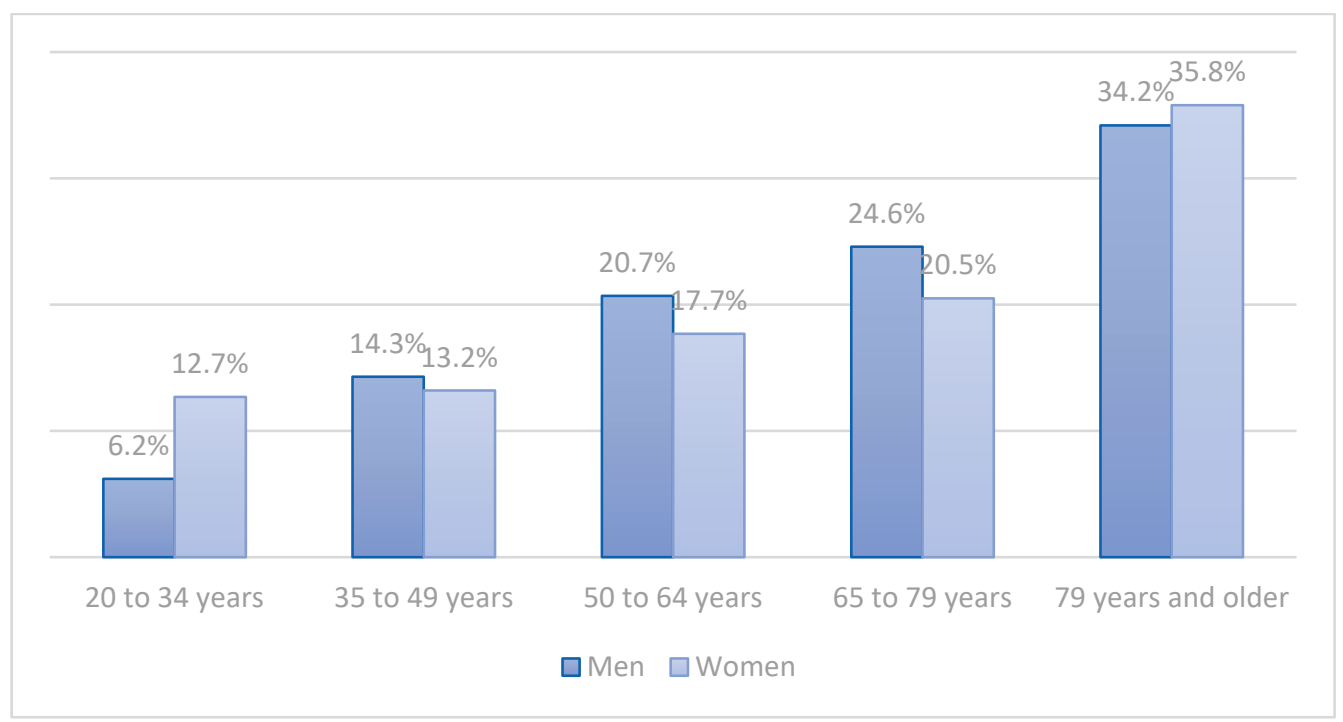

Figure 1. Distribution of conciliated patients by sex and age strata.

The prevalence of the different types of medication errors was analyzed according to patients' sex and the age, considering if the patients were under 65 , or if they were 65 or older (Table 6).

Table 6. Prevalence of medication errors, according to age and sex.

\begin{tabular}{lccc}
\hline \multicolumn{1}{c}{ Medication Errors } & Women & Men & $p^{*}$ \\
\hline $\begin{array}{l}\text { Contraindicated medication } \\
<65\end{array}$ & $63(4.9 \%)$ & $48(3.7 \%)$ & $<0.001$ \\
$>=65$ & $175(10.6 \%)$ & $180(9.6 \%)$ & $<0.01$ \\
$\begin{array}{l}\text { Duplicated medication } \\
<65\end{array}$ & $4(0.3 \%)$ & $2(0.2 \%)$ & $<0.001$ \\
$>=65$ & $11(0.7 \%)$ & $14(0.8 \%)$ & $<0.01$ \\
Medication omission & & & \\
$<65$ & $203(15.0 \%)$ & $227(17.3 \%)$ & 0.14 \\
$>=65$ & $464(28.5 \%)$ & $493(26.3 \%)$ & $<0.01$ \\
$\begin{array}{l}\text { Dossage differences } \\
<65\end{array}$ & $56(4.3 \%)$ & $65(4.9 \%)$ & $<0.05$ \\
$>=65$ & $118(7.2 \%)$ & $123(6.6 \%)$ & $<0.05$ \\
Medication interactions & $3(0.2 \%)$ & $1(0.1 \%)$ & $<0.05$ \\
$<65$ & $15(0.9 \%)$ & $13(0.7 \%)$ & $<0.05$ \\
$>=65$ & $1281(49.4 \%)$ & $1312(50.6 \%)$ & $<0.01$ \\
Conciliated patients & $1650(46.8 \%)$ & $1872(53.2 \%)$ & $<0.01$ \\
$<65$ & $\mathbf{2 9 3 1}(\mathbf{4 7 . 9 \% )}$ & $3184(\mathbf{5 2 . 1} \%)$ & $\mathbf{6 1 1 5}(\mathbf{1 0 0} \%)$ \\
\hline$=65$ & & & \\
\hline Total & & & \\
\hline
\end{tabular}

* Chi-squared test.

The medication errors were more prevalent among women 65 and older, for all kind of errors, except for duplicated medicaments, that was more prevalent among men. Medication omission was the most prevalent error, followed by contraindicated medications. Among patients under 65, the most prevalent error was medication omission, most frequent in men, and contraindicated medications, most frequent in women.

\section{Discussion}

The main aim of this research was to evaluate the systematic processing of the reconciliation of medication at hospital discharge, in a primary health care context, identifying discrepancies and medication errors. We further sought to analyze some demographic 
aspects of the patients, like age and gender, that could be associated with the occurrence of these errors.

Our results show that performing medication helps to detect discrepancies and medication errors that can be solved before the patients begin their new treatments. Other studies have stated this, for different levels of healthcare transitions $[5,13,18,19]$. Indeed, some national $[3,14,15]$ and international health agencies $[1,2,8,11,13]$ have stated that the process of medication conciliation is a useful strategy to reduce medication errors, preventing problems for patients.

Some research $[9,16-18]$ describe that, due to the complexity of the process of conciliation, it is important to follow a structured method to optimize the adequacy of the treatments to the clinical situation of the patients. Thus, potential discrepancies and medication errors that could harm the patients can be detected and evaluated. Our results confirm this, as the physicians of the Andalusian Public Health Service follow a structured method of conciliation based on an online software, which provided the database that was analyzed.

A systematic review performed on twenty interventions [5] found that most of these conciliations were performed in patients of 65 and over, poly-medicated, and in sociomedical centers and hospitals $[5,10,20]$. This high mean age, also found in our sample, seems otherwise logical, as older people usually require more hospital treatments. In addition, these patients usually need to take more medications. As a consequence of these two aspects, they are more eligible to perform the medication reconciliation process. As the studies evaluated used different methods, it was not possible to detect which conciliation methods were more effective $[12,16,21]$. Despite this, the authors concluded that discrepancies were prevalent, that they were generated in healthcare transitions, and thatthey were related to medication adverse effects, medication conciliation being the process to follow to avoid medication errors. Our findings do agree with these affirmations.

In this same research, the authors found that more than $70 \%$ of the patients analyzed, after hospital discharge, showed some kind of discrepancies in their treatment, being the mean of medication errors per patient of 2.7 . A total of $70.5 \%$ of these medication errors were found in patients 65 years and older. Other research stated a total of $42.9 \%$ of patients with discrepancies, with a mean of 2.1 medication errors per patient [7]. Other research, performed in a hospital, detected that a total of $55.1 \%$ of the admitted patients had one or more medication errors, with a mean of 3.2 medication errors per patient [21]. Several studies that performed conciliation in primary health care, after hospital discharge, found discrepancies in $40-60 \%$ of the medications of the analyzed patients $[7,12,19]$. Our figures are in concordance with these previous publications.

Regarding medication errors, omission error was the most frequent error found in our research. This finding agrees with the results of other studies, which found this error in $40-60 \%$ of the analyzed patients $[12,13,16,17]$, although we must consider that they were performed in hospitals. This is also confirmed by the Spanish Institute for Safe Medication, which stated that, in the year 2020, medication omission was the most frequent medication error, and with the most severe consequences [22].

Regarding the sex and the different age groups of the patients, the prevalence of medication errors found in our research was bigger in women of 65 and older, when compared to men of the same age. Although these differences were statistically significant, we have not found similar research with medication errors categorized by gender and groups of age. In the 20-34 age strata, the percentage of medication errors was higher for women than men, which was different from other age strata. A possible explanation for this finding is that, in that age strata, the number of women was higher than men, and there was thus a higher number of drugs prescribed to women in this age strata. Therefore, the likelihood of finding medication errors was higher among women, in this specific age strata.

Our results show that primary health care plays an essential role in the process of medication conciliation, as it is accessible for patients and caregivers, and offers a 
comprehensive vision of the patient, and its social and familiar circle $[3,12,15]$. As a conclusion, it could be useful to implement the conciliation process among all the physicians of primary health care. This way, this process could be integrated into their daily workflow, allowing the detection of numerous potential errors. To accomplish this, the support of all stakeholders and additional resources, such as more time to perform the process, are required. In addition, it could be useful to perform more research about medication conciliation in the primary healthcare environment.

Our research had some limitations. One of the most significant limitations is that our study was performed using the database of the Andalusian Public Health Service, therefore only the medication conciliations performed using this software could be analyzed. The conciliations performed in private practice, or the medications that were used by the patients but not communicated to the physicians, could not be included in this research. We must also consider that the sample was obtained from four hospital services, an aspect that could generate a potential selection bias. Therefore, these potential limitations must be considered when interpreting the external validity of our results. Our research also had some strengths. The most important is that the process of conciliation analyzed was systematic, using an online conciliation tool. This ensures that all primary care physicians followed the same process, reducing the variability of the process and therefore increasing the reliability of the analysis. Another strength of our research is that our sample size was 6115 patients, larger than the sample analyzed in other similar research.

\section{Conclusions}

After hospital discharge, most patients can show medication discrepancies in their records, these errors being more frequent in older women. Therefore, the use of a systematic process of medication conciliation by the physicians of primary health care is essential to detect and solve the medication errors that can be generated between healthcare transitions, increasing patient safety. Thus, primary health care plays an essential role in the conciliation process, so it could be useful to implant this process among all the physicians of primary health care, and to perform further research about medication conciliation in this environment. According to this, more research is needed, from the perspective of primary health care.

Author Contributions: Conceptualization, M.d.C.G.-L., C.R.-G., B.J.N.-S., S.G.-D. and T.P.-C.; methodology, M.d.C.G.-L., C.R.-G., B.J.N.-S. , S.G.-D. and T.P.-C.; formal analysis, M.d.C.G.-L., C.R.-G., B.J.N.-S. , S.G.-D. and T.P.-C.; investigation, M.d.C.G.-L., C.R.-G., B.J.N.-S. , S.G.-D. and T.P.-C.; data curation, M.d.C.G.-L., C.R.-G., B.J.N.-S. , S.G.-D. and T.P.-C.; writing-original draft preparation, M.d.C.G.-L., C.R.-G., B.J.N.-S. , S.G.-D. and T.P.-C.; writing-review and editing, M.d.C.G.-L., C.R.-G., B.J.N.-S. , S.G.-D. and T.P.-C.; supervision, T.P.-C. All authors have read and agreed to the published version of the manuscript.

Funding: This research received no external funding.

Institutional Review Board Statement: The study was conducted according to the guidelines of the Declaration of Helsinki and approved by the Research and Ethics Committee of the Province of Almeria (Spain), with protocol code TFG-ACME-2020, and approval number 07/2021 (27 January 2021).

Informed Consent Statement: Patient consent was waived due to that no personal information was collected. Therefore, no informed consent was required, as stated by the Institutional Review Board of Research and Ethics Committee of the Province or Almeria (Spain).

Data Availability Statement: All data are contained within the article.

Conflicts of Interest: The authors declare no conflict of interest. 


\section{References}

1. World Health Organization. World Alliance for Patient Safety Progress. 2008. Report 2006-2007. World Health Organization. Available online: https:/ /apps.who.int/iris/handle/10665/75169 (accessed on 15 October 2021).

2. National Institute for Health and Care Excellence (NICE). National patient safety. Agency Technical Patient Safety Solutions for Medicines Reconciliation on Admission of Adults to Hospital. United Kingdom; 2008. Available online: https://www.sefap.org/ media/upload/arxius/formacion/aula_fap_2010/bibliografia/NHS_Technical_patient_safety_solutions.pdf (accessed on 15 October 2021).

3. Patient Safety Strategy of the Spanish National Health Service 2015-2020. Spanish Ministry of Health. Madrid, 2015. Available online: https: / / seguridaddelpaciente.es/es/informacion/publicaciones / 2015/estrategia-seguridad-del-paciente-2015-2020/ (accessed on 15 October 2021).

4. World Health Organization. Medication without Harm-Global Patient Safety Challenge on Medication Safety. Geneva: WHO; 2017. Available online: https:/ /apps.who.int/iris/bitstream/handle/10665/255263/WHO-HIS-SDS-2017.6-eng.pdf (accessed on 15 October 2021).

5. Kwan, J.L.; Lo, L.; Sampson, M.; Shojania, K.G. Medication Reconciliation During Transitions of Care as a Patient Safety Strategy. Ann. Intern. Med. 2013, 158, 397. [CrossRef] [PubMed]

6. Wheeler, A.J.; Scahill, S.; Hopcroft, D.; Stapleton, H. Reducing medication errors at transitions of care is everyone's business. Aust. Prescr. 2018, 41, 73-77. [CrossRef] [PubMed]

7. Valverde, E.; Mendizabal, A.; Ariz, C.; Mitxelena, I.; Pérez, A.; Igea, V. Conciliación de la medicación: Desde el ingreso hasta la atención primaria. Rev. Calid. Asist. 2016, 31, 62-65. [CrossRef]

8. Joint Commission. National Patient Safety Goals. 2011. Available online: www.jointcommission.org/standards_information/ npsgs.aspx (accessed on 15 October 2021).

9. Khalil, H.; Shahid, M.; Roughead, L. Medication safety programs in primary care: A scoping review. JBI Database Syst. Rev. Implement Rep. 2017, 15, 2512-2526. [CrossRef] [PubMed]

10. Redmond, P.; Grimes, T.C.; McDonnell, R.; Boland, F.; Hughes, C.; Fahey, T. Impact of medication reconciliation for improving transitions of care. Cochrane Database Syst. Rev. 2018, 2018. [CrossRef] [PubMed]

11. The Institute for Safe Medication Practices. Medication Safety Support Service. Horsham. England. Institute for Safe Medication Practices (ISMP). 2011. Available online: https://psnet.ahrq.gov/resources/resource/2616/the-institute-for-safe-medicationpractices (accessed on 15 October 2021).

12. Pharmaco-Therapeutic Information (INFAC, Osakidetza). Medication Conciliation. Public Health Department of Gipuzkoa, Basque Government. 2013, 21, 10.2013. Available online: https://www.osakidetza.euskadi.eus/contenidos/informacion/ cevime_infac_2013/es_def/adjuntos/INFAC_Vol_21_n_10.pdf (accessed on 15 October 2021).

13. The Canadian Agency for drugs and technologies in health. Medication Reconciliation at Discharge: A Review of the Clinical Evidence and Guidelines. Rapid Response Report. Summary with critical appraisal. CADTH. 2012. Available online: https:/ / www.cadth.ca/media/pdf/htis/april-2012/RC0339\%20-\%20Medication\%20Reconciliation\%20Final.pdf (accessed on 15 October 2021).

14. Agency for Quality of the National Spanish Public Health System. National Study on adverse effects related to hospitalization: ENEAS. Spanish Ministry of Health. Madrid. 2005. Available online: https://seguridaddelpaciente.es/resources/contenidos/ castellano/2006/ENEAS.pdf (accessed on 15 October 2021).

15. Agency for Quality of the National Spanish Public Health System. National Study on Patient Safety in Health Primary Care: APEAS. Spanish Ministry of Health. Madrid. 2008. Available online: https://www.mscbs.gob.es/organizacion/sns/ planCalidadSNS/docs/estudio_apeas.pdf (accessed on 15 October 2021).

16. Mekonnen, A.B.; Abebe, T.B.; McLachlan, A.J.; Brien, J.E. Impact of electronic medication reconciliation interventions on medication discrepancies at hospital transitions: A systematic review and meta-analysis. BMC Med. Inform. Decis. Mak. 2016, 16, 112. [CrossRef] [PubMed]

17. Zara, C.; Amado, E.Y.; Rosich, I. Chronic Patient Medication Management: Conciliation, Revision and Adherence. Department of Health, Government of Catalonia. 2014. Available online: https://scientiasalut.gencat.cat/bitstream/handle/11351/1477 /medicacion_paciente_cronico_catalu na_cas_2014.pdf?sequence=9\&isAllowed=y (accessed on 15 October 2021).

18. Kim, J.M.; Suarez-Cuervo, C.; Berger, Z.; Lee, J.; Gayleard, J.; Rosenberg, C.; Nagy, N.; Weeks, K.; Dy, S. Evaluation of Patient and Family Engagement Strategies to Improve Medication Safety. Patient-Patient-Cent. Outcomes Res. 2018, 11, 193-206. [CrossRef] [PubMed]

19. Kee, K.; Char, C.T.; Yip, A.F. A review on interventions to reduce medication discrepancies or errors in primary or ambulatory care setting during care transition from hospital to primary care. J. Fam. Med. Prim. Care 2018, 7, 501. [CrossRef] [PubMed]

20. Liu, V.C.; Mohammad, I.; Deol, B.B.; Balarezo, A.; Deng, L.; Garwood, C.L. Post-discharge Medication Reconciliation: Reduction in Readmissions in a Geriatric Primary Care Clinic. J. Aging Health 2019, 31, 1790-1805. [CrossRef] [PubMed]

21. González-García, L.; Salmerón-García, A.; García-Lirola, M.; Moya-Roldán, S.; Belda-Rustarazo, S.; Cabeza-Barrera, J. Medication reconciliation at admission to surgical departments. J. Eval. Clin. Pract. 2016, 22, 20-25. [CrossRef] [PubMed]

22. Institute for Safe Medication (ISMP-Spain). Recommendations for the Prevention of Medication Errors Bulletin; Spanish Ministry of Health: Madrid, Spain, 2021; Volume 50, pp. 1-5. Available online: http://www.ismp-espana.org/ficheros/Boletin \%2050\%20\% 28Febrero\%202021\%29.pdf (accessed on 15 October 2021). 